\title{
SV40-Transformed Human Corneal Keratocytes: Optimisation of Serum-free Culfure Conditions
}

\author{
Anna Katharina Manzer ${ }^{1}$, Simone Lombardi-Borgial ${ }^{1}$, Monika Schäfer-Korting ${ }^{1}$, \\ Judith Seeber ${ }^{1}$, Michaela Zorn-Kruppa ${ }^{2}$ and Maria Engelke ${ }^{2}$ \\ ${ }^{1}$ Institute of Pharmacy, Free University, Berlin, Germany; ${ }^{2}$ German Animal Welfare Federation - Animal Welfare Academy, \\ Neubiberg, Germany
}

\begin{abstract}
Summary
Aiming at the replacement of animal experiments in eye irritation testing, we have established a multilayered cornea model comprising the co-culture of all three corneal cell types. It was the objective of this study to optimise serum-free culture conditions to preserve both growth and phenotype of an SV40-immortalised human corneal keratocyte cell line (HCK). Our results revealed that HCK continue to proliferate in both monolayer cultures as well as after seeding in a collagen matrix and resemble primary corneal keratocytes in morphology and functional characteristics under defined serum-free conditions. Furthermore, HCK were shown to transform into activated corneal fibroblast phenotypes in response to serum and TGF $\beta 1$. In summary, HCK cells mimic their in vivo (primary) precursors, both in sustaining the quiescent keratocyte phenotype (serum-starved conditions) and in responding to growth factor stimulation. Hence, this cell line may provide a useful tool to study the toxicity and wound healing response of corneal keratocytes in vitro.
\end{abstract}

Keywords: SV40-immortalised human keratocytes, myofibroblast differentiation, collagen gel contraction, $T G F \beta 1, \alpha-S M A$

\section{Introduction}

Currently, there is no accepted alternative regulatory method to eliminate the use of animals in ocular irritation testing for the risk assessment of chemicals, pharmaceuticals and cosmetics. According to an ESAC statement sufficient data support the use of the Bovine Corneal Opacity and Permeability (BCOP) test method, and the isolated chicken eye (ICE) test method as screening tests to identify substances as ocular corrosives or severe irritants in a tiered-testing strategy. Very mild irritants may soon be identified by commercially available, three-dimensional models of the corneal epithelium. However, the gap between mild and moderate eye irritation potential has to be closed by new alternative methods and the call for a mechanistically based method that considers the depth of the corneal injury and hence covers the whole severity range of toxic reactions, demands an implementation of corneal structures, such as stroma and endothelium, in an organotypic in vitro model of the human cornea (Maurer et al., 2002; Maurer et al., 2001; Jester et al., 2001; Jester, 2006). Most ocular irritants cause progressive injury to the cornea with stromal injury occurring beneath the areas of epithelial denudation. Clear exceptions to this rule are some chemicals (Maurer et al., 2001) which are more harmful to the stroma than to the epithelium. This observation highlights the need to include both epithelial and stromal components in an in vitro model as focusing only on the epithelium would underestimate the injury occurring with certain chemicals like for example hydrogen peroxide. Assays using only stratified epithelium are restricted to the detection of those materials causing only slight irritation, whereas the inclusion of stroma and stromal keratocytes broadens the range of potential irritation that can be detected.

Aiming at the establishment of a multilayered cornea model to replace animal experiments in eye irritation testing, our work focuses on the optimisation of an existing full-thickness-model of the human cornea constructed from three SV40-immortalised human cell lines (Engelke et al., 2004; Zorn-Kruppa et al., 2005) with regard to standardised serum-free culture conditions for all the three different cell types of this tissue engineered cornea. They are grown in co-culture for several days, and some serum components are known to stimulate keratocyte differentiation into the contractile myfibroblast type. In this context, the SV40immortalised human keratocyte cell line (HCK) (Zorn-Kruppa 
et al., 2004) was characterised with regard to the preservation of cell specific features in spite of the SV40-immortalisation, culture medium and its serum content.

This study presents cell proliferation kinetics and phenotypical alterations of the HCK cell line (Zorn-Kruppa et al., 2004) under serum-free conditions in monolayer cell culture and after incorporation into a collagen gel matrix which reflects the stromal architecture. In addition, the response of HCK to TGF $\beta 1$ was studied together with the functional capacity of this cell line to contract the collagen matrix as a result of myofibroblast differentiation.

In the intact cornea in vivo, keratocytes are mitotically quiescent cells that establish a dendritic morphology (Fini, 1999). After isolation, these cells can maintain a dendritic, keratocyte morphology in vitro when grown in the absence of serum (Kawakita et al., 2006), while differentiation into the myofibroblast phenotype can be induced by the addition of serum, TGF $\beta$ or certain growth factors (Beales et al., 1999; Jester et al., 1996; Jester and Ho-Chang, 2003; Masur et al., 1996). Serum alone can exert a detrimental effect on the maintenance of the keratocyte phenotype due to its TGF $\beta$ content, which is known to stimulate keratocyte transformation into fibrotic cell types (Borderie et al., 1999; Masui et al., 1986). Alterations in the cellular phenotype become apparent as changes in cell shape, actin reorganisation, the expression of focal adhesion proteins and the formation of adherens or gap junctions, respectively (Fini, 1999; Fini and Stramer, 2005). The extent of transformation from keratocytes to myofibroblast-like cells is indicated by the development of prominent microfilament bundles containing $\alpha$-smooth-muscle-specific actin ( $\alpha$-SMA) (Jester et al., 1996; Jester et al., 1999). While the quiescent phenotype is non-contractile, environmental factors that lead to phenotypical alterations can also cause functional changes regarding the cellular capacity to contract the extracellular matrix (Jester and Ho-Chang, 2003). Cellular quiescence is obtained and preserved exclusively in serum-free media, resulting in the keratocyte phenotype (Berryhill et al., 2002; Kawakita et al., 2006).

In the present study we evaluated whether the SV40-immortalised keratocytes maintain quiescent keratocyte characteristics under appropriate culture conditions and respond to serum and TGF $\beta$ stimulation like their in vivo (primary) precursors.

\section{Materials and methods}

\subsection{Chemicals}

Medium 199 (M199), Ham's Nutrient Mixture F12 (Ham's F12), antibiotic-antimycotic solution $(10,000 \mathrm{U}$ penicillin, 10,000 U streptomycin and $25 \mu \mathrm{g} / \mathrm{ml}$ amphothericin B) and Oregon Green ${ }^{\circledR}$ 488-labeled phalloidin were purchased from Gibco-Invitrogen (Karlsruhe, Germany). Fetal calf serum (FCS) was provided by Biochrom (Berlin, Germany). Keratinocyte growth medium $\left(\mathrm{KGM}^{\circledR}\right)$, which is composed of keratinocyte basal medium $\left(\mathrm{KBM}^{\circledR}\right)$, and $\mathrm{KGM}^{\circledR}$ SingleQuots $(0.1 \mathrm{ng} / \mathrm{ml}$ recombinant EGF, $5.0 \mu \mathrm{g} / \mathrm{ml}$ insulin, $0.5 \mu \mathrm{g} / \mathrm{ml}$ hydrocortisone, $0.15 \mathrm{mM} \mathrm{Ca}^{2+}$, $30 \mu \mathrm{g} / \mathrm{ml}$ bovine pituitary extract, $50 \mu \mathrm{g} / \mathrm{ml}$ gentamicin sulfate, and $50 \mathrm{ng} / \mathrm{ml}$ amphotericin B) were obtained from Lonza (Wuppertal, Germany).

Murine monoclonal anti- $\alpha$-SMA, anti-mouse IgG-FITC secondary antibody, human transforming growth factor $\beta 1$ (TGF $\beta 1$ ), aprotinin, bovine serum albumin (BSA), bromophenol blue, collagenase from Clostridium histolyticum, type I collagen from rat tail, deoxycholic acid, dimethyl sulphoxide (DMSO), dithiothreitol (DTT), ethylenediaminetetraacetic acid (EDTA), gelatine from cold water fish skin, glycerol, goat serum, HEPES, isopropanol, leupeptin, Mowiol ${ }^{\mathrm{TM}}$, 3-[4,5-dimethylthiazol-2-yl]-2, 5-diphenyl tetrazolium bromide (MTT), $\mathrm{NaHCO}_{3}$, $\mathrm{NaOH}$, Nonidet P-40, pepstatin, phenylmethanesulfonyl fluoride (PMSF), sodium azide, sodium chloride, sodium dodecyl sulphate (SDS), sodium fluoride, calcium chloride, sodium orthovanadate, Tris, Tris/HCl, Triton X-100 and Tween 20 were purchased from SIGMA-Aldrich (Deisenhofen, Germany). Goat Indocarbocyanin $\left(\mathrm{Cy}^{\mathrm{TM}_{3}}\right)$-conjugated anti-mouse $\mathrm{IgG}$ was obtained from Dianova (Hamburg, Germany). Secondary anti-mouse IgG conjugated with horseradish peroxidase (HRP), as well as LumiGlo ${ }^{\mathrm{TM}}$ reagent and Peroxide Reagent B were obtained from New England Biolabs (Frankfurt, Germany).

Normal Goat Serum Blocking Solution IHC was prepared from $2 \%$ goat serum, $1 \%$ BSA, $0.1 \%$ cold fish skin gelatine, $0.1 \%$ Triton $\mathrm{X}-100,0.05 \%$ Tween 20 and $0.05 \%$ sodium azide in $0.01 \mathrm{M}$ PBS, adjusted to $\mathrm{pH} 7.2$ and stored at $-20^{\circ} \mathrm{C}$ until use.

\subsection{Cell culture}

The immortalised human corneal keratocyte (HCK) cell line (Zorn-Kruppa et al., 2004) was derived from primary human keratocytes transfected with a mammalian expression vector containing genes encoding for the SV40 early region.

For routine culture, HCK cells were grown in basal medium F99, a 1:1 mixture of Medium 199 (M199) and Ham's Nutrient Mixture F12 (Ham's F12) supplemented with 5\% fetal calf serum (FCS), and $1 \%$ antibiotic-antimycotic solution in a $5 \%$ $\mathrm{CO}_{2}$ atmosphere at $37^{\circ} \mathrm{C}$. Cultures were serially passaged twice a week.

To study cell proliferation and cell phenotype under serumfree conditions, HCK were adapted to keratinocyte growth medium $\left(\mathrm{KGM}^{\circledR}\right)$ supplemented with calcium chloride to a final concentration of $0.5 \mathrm{mM}$ (KGM-Ca). HCK were adapted to serum-free media for at least ten and maximum fifteen passages before they were used for further tests.

\subsection{Preparation of three-dimensional stromal collagen matrices}

The collagen matrix for the construction of an artificial stroma was prepared according to Zorn-Kruppa (Zorn-Kruppa et al., 2005) with minor modifications. Briefly, rat tail type I collagen was dissolved in sterile $0.1 \%$ acetic acid ( $\mathrm{pH} 3.3$ ). Five volumes of the acid-soluble collagen solution were gently mixed with one volume of ten-fold concentrated F99 medium, one volume of reconstruction buffer $\left(2.2 \mathrm{~g}\right.$ of $\mathrm{NaHCO}_{3}$ and $4.77 \mathrm{~g}$ HEPES in $100 \mathrm{ml} 0.05 \mathrm{~N} \mathrm{NaOH}$ ) and one volume of FCS containing $1 \times 10^{5} \mathrm{HCK}$ cells. Tissue culture polycarbonate membrane inserts $(0.4 \mu \mathrm{m}$ pore size and $10 \mathrm{~mm}$ diameter; Nunc, Wiesbaden, 
Germany), were placed in 6-well plates. The collagen-cell-suspension was pipetted into these inserts and allowed to polymerise for 1 hour at $37^{\circ} \mathrm{C}$. After completed polymerisation the artificial stromal matrices were cultured in submersion by adding 3 $\mathrm{ml}$ of serum-containing F99 medium to each well.

Serum-free collagen matrices were constructed by mixing two volumes of KGM-Ca medium containing $1 \times 10^{5} \mathrm{HCK}$, which had been adapted to serum-free medium, with one volume of reconstruction buffer and five volumes of the acid-soluble collagen solution.

\subsection{Analysis of cellular proliferation}

Cell proliferation was determined by Fluorescence Activated Cell Sorting (FACS). Cells were seeded in 24-well plates at a density of $5 \times 10^{3} /$ well, changing medium every second day. For FACS analysis cells were completely detached by incubation with a solution of $0.25 \%$ trypsin and $0.2 \%$ EDTA $(200 \mu \mathrm{l} /$ well) at $37^{\circ} \mathrm{C} 5 \% \mathrm{CO}_{2}$ for five minutes. Cells were resuspended in $500 \mu 1$ medium and transferred to an ice cooled FACS tube. Samples were vortexed carefully just prior to the measurement. The experiment was performed with a FACSCalibur ${ }^{\mathrm{TM}}$ Flow Cytometry System (Becton Dickinson, San Jose, CA). Data were analysed using the CellQuest software package (BD Biosciences, Heidelberg, Germany).

The proliferation of HCK in the artificial stroma was determined using the MTT viability assay (Mossmann, 1983). On day $1,3,6,10$ and 14 the inserts were transferred to 6-wellplates containing $300 \mu \mathrm{l} \mathrm{MTT}(1 \mathrm{mg} / \mathrm{ml})$ in the corresponding medium. After a three hour incubation period $\left(37^{\circ} \mathrm{C}, 5 \% \mathrm{CO}_{2}\right)$ the solvent was aspired, gels were rinsed three times with PBS, dried by blotting on sterile paper and transferred to a 24-wellplate. Formazan was extracted by $2 \mathrm{ml}$ isopropanol for 24 hours at room temperature in the dark. The plates were sealed with parafilm to avoid solvent evaporation. Then the inserts were pierced with an injection needle to let the extraction solution run into the corresponding well, and the plate was shaken until the solution was of homogeneous colour. The optical density was measured at $570 \mathrm{~nm}$. Absorbance increased linearly with cell number as quantified by counting under the microscope.

\subsection{Immunofluorescent microscopy}

HCK cells were plated at $5 \times 10^{4}$ /chamber on four-well Lab$\mathrm{Tek}^{\mathrm{TM}}$ II Chamberslides (Nunc, Wiesbaden, Germany) and grown in either serum-containing or serum-free medium up to $80 \%$ confluency. Cells were exposed to $2 \mathrm{ng} / \mathrm{ml}$ TGF $\beta 1$ for three days in order to stimulate them to differentiate into myofibroblasts. For immunostaining the cells were washed twice in cold PBS containing $0.5 \mathrm{mM} \mathrm{CaCl}_{2}$ and $1 \mathrm{mM} \mathrm{MgCl}_{2}$, fixed in $4 \%$ paraformaldehyde (in PBS) for 10 minutes and permeabilised with $0.1 \%$ Triton $\mathrm{X}-100$ for 5 minutes at room temperature. Cells were treated with Normal Goat Serum Blocking Solution IHC for 30 minutes and incubated with anti $\alpha$-SMA mouse monoclonal antibody to identify myofibroblast differentiation. Indocarbocyanin-labeled anti-mouse $\operatorname{IgG}$ (Cy3) was used to visualise the primary antibodies. F-actin-containing stress fibers were visualised with Oregon Green ${ }^{\circledR}$ 488-labeled phalloidin. Each step was separated by 3 x 5-minute washes with PBS.
The cells on the coverslips were fixed by a Mowiol ${ }^{\mathrm{TM}}$ mounting medium and viewed with an Olympus BX41 fluorescence microscope (Olympus, Hamburg, Germany). Pictures were taken with a Nikon DXM1200 digital camera (Nikon, NY, USA). Appropriate emission filter settings and controls were included to reduce background fluorescence.

\subsection{Western blot analysis}

HCK cells were plated at $2.5 \times 10^{4} /$ well on 6-well-plates (Nunc, Wiesbaden, Germany) and grown in either serum-containing or serum-free medium, partly in the presence of $2 \mathrm{ng} / \mathrm{ml} \mathrm{TGF} \beta 1$. For cell lysis, HCK were rinsed twice with ice-cold PBS and harvested in RIPA buffer [50 mM Tris/ $\mathrm{HCl}, \mathrm{pH} 7.5,150 \mathrm{mM}$ $\mathrm{NaCl}, 1 \%$ Nonidet P-40, $0.5 \%$ deoxycholic acid, $0.1 \%$ SDS], containing protease inhibitors [1mM PMSF, 1mM EDTA, 1 $\mu \mathrm{g} / \mathrm{ml}$ leupeptin, $1 \mu \mathrm{g} / \mathrm{ml}$ aprotinin and $1 \mu \mathrm{g} / \mathrm{ml}$ pepstatin] and phosphatase inhibitors $[1 \mathrm{mM}$ sodium orthovanadate, $50 \mathrm{mM}$ sodium fluoride and $40 \mathrm{mM} \beta$-glycerophosphate]. Cell lysates were centrifuged at $14,000 \mathrm{~g}$ for $30 \mathrm{~min}$ to remove the cellular debris. Two volumes of the supernatant containing $20 \mu \mathrm{g}$ of protein were mixed with one volume of SDS sample buffer [100 $\mathrm{mM}$ Tris $/ \mathrm{HCl}, \mathrm{pH} 6.8,4 \%$ SDS, $0.2 \%$ bromophenol blue, $20 \%$ glycerol, $200 \mathrm{mM}$ DTT] and boiled for $2 \mathrm{~min}$ at $95^{\circ} \mathrm{C}$ to elute the lysate proteins.

For Western blot analysis of $\alpha$-SMA expression, lysates of the stimulated and non-stimulated HCK were separated by SDS/ PAGE. Gels were blotted overnight onto PVDF-membranes. After blocking with 5\% non-fat dry milk in TBS-Tween 20 $(0.1 \%)$ for one hour at $4^{\circ} \mathrm{C}$, membranes were incubated with monoclonal $\alpha$-SMA antibody at a 1:12,500 dilution for $40 \mathrm{~min}$ utes at room temperature. The blots were washed three times in TBS-Tween 20 followed by incubation with secondary antimouse antibody conjugated to horseradish peroxidase (HRP) for $1 \mathrm{~h}$ at room temperature. Immuno-complexes were detected using an enhanced chemiluminescence detection method. Each experiment was performed three times in duplicate.

For the detection and semi-quantification of the $\alpha$-SMA expression of HCK in the collagen matrix, cells were released from the gel by collagenase digestion after a culture period of six days. For this purpose, the gels were detached from their inserts and incubated in a 10:1 mixture of collagenase $(2.5 \mathrm{mg} / \mathrm{ml})$ and $0.5 \%$ trypsin at $37^{\circ} \mathrm{C}$ for $2 \mathrm{~h}$ on a shaker. After two rounds of centrifugation and washing in cold PBS, cells were subjected to lysis, protein was extracted from the cell pellet and Western blot analysis was performed as described above.

\subsection{Collagen matrix contraction}

Serum-containing and serum-free stromal equivalents were prepared as described above by incorporating the appropriate HCK density into the collagen matrix. After three days of submerged culture, part of the tissues were stimulated with TGF $\beta 1$ (2 ng/ $\mathrm{ml}$ ) for another three days. Collagen gel contraction was determined on day six. Photographs of the gels were taken using an Olympus SZX12 stereomicroscope with a ColorView IIIu digital camera and cell^A image analysis software (Olympus, Hamburg, Germany). The area of each gel was determined with the AxioVision software programme from Zeiss (Carl-Zeiss, Jena). 
The average contraction was calculated from the decrease of the gel's surface in relation to the gel surface after plating.

\section{Results}

\subsection{HCK proliferation in monolayer and 3D collagen matrix}

The proliferation kinetics of HCK have been studied in several serum-free media. Most of the media supported the proliferation of cultured HCK cells, but calcium-supplemented KGM was the most efficient medium for prolonged cultivation of the cell line without serum. Figure 1A illustrates that proliferation kinetics of HCK plated in serum-supplemented F99 routine medium or in serum-free KGM-Ca medium are comparable.

HCK cells showed a very different proliferation profile in 3D collagen cultures compared to monolayers (Fig. 1A and 1B). Figure 1B shows cell growth behaviour of HCK embedded in either serum-supplemented or serum-free collagen matrices for 14 days. Apparently, HCK under serum-free conditions stop proliferation after 6 days in 3D culture. A contact inhibition effect may support the differences between the different conditions (matrix vs. monolayer). However, HCK adapted to serumstarved conditions proliferated to a much higher extent than serum-supplemented HCK in 3D cultures. This inhibition effect observed in serum-supplemented collagen matrixes may result from gel contraction, which reduces inter-cellular distances.

\subsection{HCK phenotype in monolayer culture}

The alterations in the phenotype of keratocytes cultivated in different media were changes in cell shape, actin reorganisation and $\alpha$-smooth muscle actin ( $\alpha$-SMA) expression. Figure 2 shows HCK cultivated in either serum-free KGM-Ca (Fig. 2A), after stimulation with TGF $\beta$ (Fig. 2B) or in routine serum-containing F99 medium (Fig. 2C). Adaptation of HCK to serum-free KGM$\mathrm{Ca}$ medium resulted in the reduction of cellular differentiation, as shown by the predominantly stellate morphology of a quies- cent, non activated phenotype and the typical cortical F-actin organisation, lacking filament assembly and $\alpha$-SMA staining (Fig. $2 \mathrm{~A})$. In contrast, both TGF $\beta$ stimulation and serum-containing culture conditions caused transformation into fibroblast-like cells together with loss of the dendritic keratocyte shape and development of a very large, spread morphology. Those features are an indication for myofibroblast differentiation, which was verified by a positive staining of $\alpha$-SMA (Fig. 2B, C).

The immunocytochemical results were confirmed by blotting proteins against antibodies specific for $\alpha$-SMA (Fig. 3). Almost no myofibroblast-specific $\alpha$-SMA is expressed in the absence of serum (lane 3 ). In contrast, both the addition of serum and TGF $\beta 1$ induced $\alpha$-SMA expression (lane $1,2,4$ ).

We also investigated the time dependence of the TGF $\beta 1$ induced phenotypic alteration in HCK cells. For this purpose, we followed the expression of $\alpha$-SMA after addition of TGF $\beta 1$ on the day of seeding by Western blot analysis over seven days. As expected, HCK cultivated in serum-containing medium appeared differentiated to a certain extent, even without TGF $\beta 1$ stimulation. Addition of TGF $\beta 1$ resulted in a further increase in $\alpha$-SMA expression with a maximum at day three and four (Fig. 4A). As already shown by the immunocytochemistry results, serum-free cultured HCK exhibited almost no inherent myofibroblast differentiation, but were responsive to TGF $\beta 1$ stimulation with maximum $\alpha$-SMA expression on day four after seeding and stimulation, respectively (Fig. 4B).

\subsection{Phenotype of HCK embedded into a 3D collagen gel matrix}

The phenotype of HCK embedded in the artificial stromal matrices was also assessed by means of $\alpha$-SMA expression (Fig. 5). HCK cultured under serum-free conditions for six days reflected an undifferentiated phenotype without $\alpha$-SMA expression (lane 1). Lane 2 shows the profound augmentation of $\alpha$-SMA in these cells reflecting a strong myofibroblast differentiation as a response to TGF $\beta 1$ stimulation of the collagen culture. Under serum-containing conditions, HCK appeared to be partially dif-
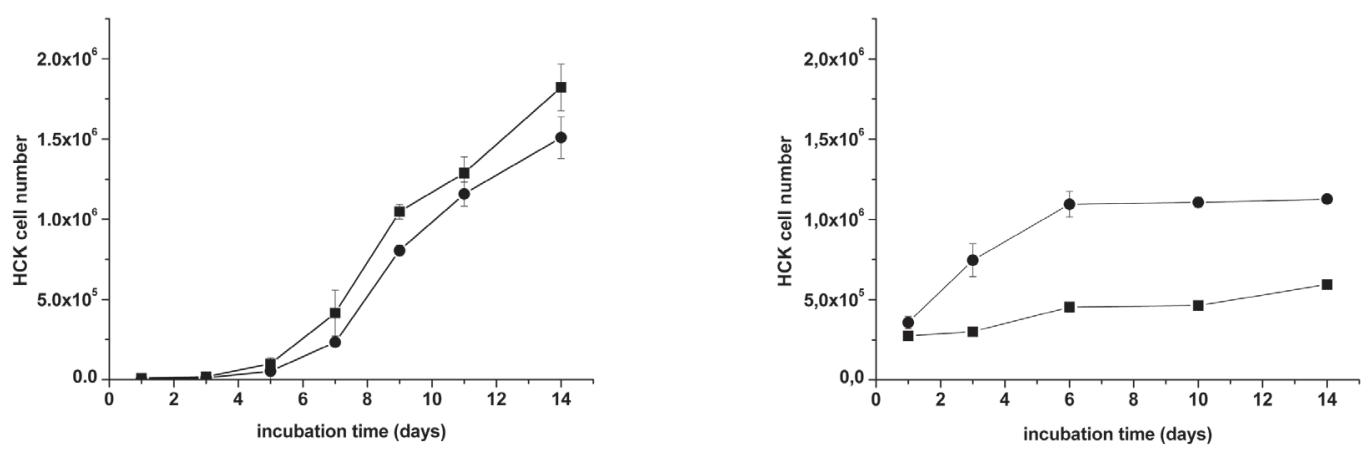

Fig. 1: Proliferation of HCK (mean \pm SD) in F99 $+5 \%$ FCS $(\square)$ or serum-free KGM-Ca (O).

Proliferation in monolayer cultures (A) and in three-dimensional type I collagen gels (B). Cell viability was assessed using FACS analysis or MTT assay, respectively. 


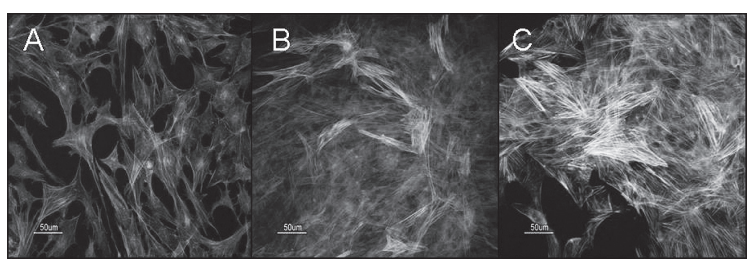

Fig. 2: Stellate morphology of the quiescent, non activated phenotype of HCK cells with typical F-Actin organisation in serum-starved medium (A). Myofibroblast differentiation induced after TGF $\beta$ stimulation (B) or addition of serum (C) as shown by anti-a-SMA staining.

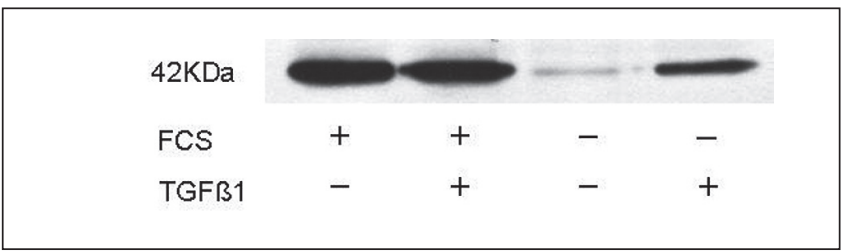

Fig. 3: Western blot analysis of a-SMA expression in serum-containing medium without (lane 1) and after $72 \mathrm{~h}$ TGF $\beta 1$ treatment (lane 2). In contrast, $\alpha$-SMA expression is suppressed in untreated keratocytes in serum-free medium (lane 3), but can be induced by TGF $\beta 1$ (lane 4).

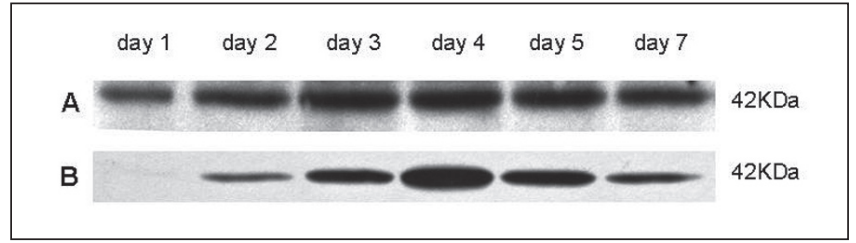

Fig. 4: Western blot analysis of time dependent a-SMA expression.

TGF $\beta 1$ was added on the day of seeding (day 0). In both serumfree and serum-containing medium, $\mathrm{HCK}$ are sensitive to TGF $\beta 1$ stimulation. Under serum-containing conditions cells showed anti-aSMA staining already on day one (A). a-SMA expression increased with time until day three. Under serum-free culture conditions (B), HCK showed maximum protein expression on day four.

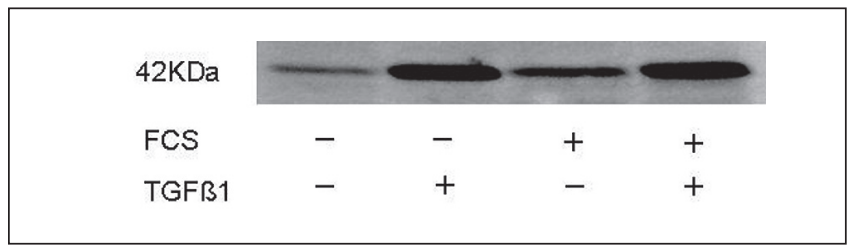

Fig. 5: Western blot analysis of a-SMA expression in HCK after six days embedding in the three dimensional stromal collagen gel.

Cells were cultivated in a stromal matrix composed of type I collagen \pm serum and exposed to TGF $\beta 1(2 \mathrm{ng} / \mathrm{ml})$ for three days.
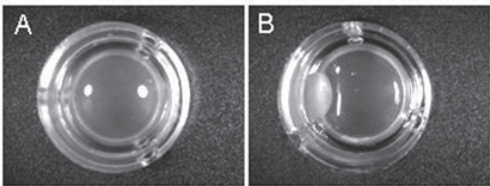

FCS

TGFß1

contraction

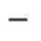

$-$

$0 \pm 6.6 \%$

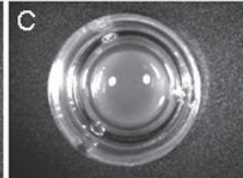

$+$

$-$

$37.9 \pm 0.8 \%$

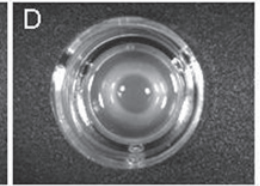

$+$

$+$

$52.6 \pm 1.6 \%$

Fig. 6: Collagen matrix contraction assay showing the contractile properties of HCK in serum-free (A and B) and serumcontaining collagen gels (C and $D)$.

Three days stimulation with $2 \mathrm{ng} / \mathrm{ml}$ TGF $\beta 1$ resulted in dramatic gel contraction in the serum-deprived (B) and serum-containing collagen matrices (D). The average collagen matrix contraction (mean $\pm \mathrm{SD}$ ) under different conditions was calculated from the decrease of the gel's surface area as \% of the gel surface after plating. Each experiment was conducted with 3-6 tissues. The average contraction and standard deviation (SD) was calculated using weighted arithmetic means.

ferentiated without growth factor (lane 3), hence, the increase in $\alpha$-SMA expression after addition of TGF $\beta 1$ was less obvious (lane 4).

\subsection{Collagen matrix contraction as a result of myofibroblast differentiation}

We studied whether the phenotypical changes in HCK were paralleled by an altered contractile behaviour. Photographs of serum-free and serum-containing collagen matrices after a six day incubation period show that the presence of serum and/ or TGF $\beta 1$ induced a remarkable gel contraction (Figs. 6B, C, D). In contrast, gel contraction was not observed in tissue cultures of HCK under serum-free conditions (Fig. 6A). The aver- age contraction under different conditions was calculated from the decrease of the gels' surface in relation to the average gel surface after plating. Collagen matrix contraction confirms the $\alpha$-SMA expression in the stromal cells.

\section{Discussion}

The objective of this study was to formulate a medium for monolayer culture and $3 \mathrm{D}$ collagen gel matrix population to optimise both growth and restoration of the keratocyte phenotype of the cell line HCK, which was derived from human keratocytes by SV40-transfection. The immortalisation of 
corneal fibroblasts using SV40-infection of rabbit keratocytes has already been reported (Barry-Lane et al., 1997). The problem therein was that this transformed cell-line exhibited a myofibroblast phenotype with constitutive expression of $\alpha$-SMA that could not be upregulated upon addition of TGF $\beta$. General problems with the use of the SV40 oncogene are a possible chromosomal instability after immortalisation, block of downstream cell differentiation (Hoffschir et al., 1992) as well as loss of contact inhibition and growth control (Wilson et al., 1993; 1995).

Our results show that the HCK cell line can be induced to grow and differentiate in culture to both keratocyte-like and myofibroblast-like phenotypes. These cell types can be distinguished based on cell shape, structural organisation and contractile behaviour (Fini, 1999; Jester and Ho-Chang, 2003; Jester et al., 2003). Under serum-free conditions, HCK continued to proliferate and could be subcultured for at least 10 passages while maintaining a non-contractile, keratocyte phenotype. The presence of serum and/or TGF $\beta$ induced dramatic alterations in morphology, biophysical features and function. These factors are known to promote myofibroblast differentiation, which finally results in collagen gel contraction (Borderie et al., 1999; Masui et al., 1986).

When grown in the absence of serum, HCK appeared similar to quiescent corneal keratocytes in vivo, including the maintenance of a stellate/ dendritic morphologic appearance with poorly organised microfilament bundles. The inability to contract extracellular matrix under serum-free conditions was another feature of HCK cells, which went along with a lack of $\alpha$-SMA expression. This finding was consistent with previous reports on primary stromal cells (Kawakita et al., 2006), demonstrating the preservation of a keratocyte-like phenotype. Addition of TGF $\beta 1$ to serum-free cultures enhanced $\alpha$-SMA expression in HCK along with the development of the typical large-spread morphology of in vitro myofibroblasts (Fini, 1999; Jester et al., 2003; Jester et al., 1995; Masur et al., 1996). This phenotypic shift is consistent with the previously reported TGF $\beta$-induced changes in morphology and the upregulation of $\alpha$-SMA in cultured primary keratocytes (Assouline et al., 1992; Jester et al., 1996; Jester et al., 1999; Petridou et al., 2000). Moreover, in the presence of TGF $\beta 1$, HCK became capable of contracting collagen gels, demonstrating the conversion of keratocytes to myofibroblasts along with the loss of keratocyte-like characteristics (Assouline et al., 1992; Jester and Ho-Chang, 2003; Kurosaka et al., 1998).

In serum-containing standard medium HCK expressed myofibroblast-like features even without TGF $\beta 1$ stimulation. The addition of $5 \%$ FCS caused a loss of the dendritic morphology in part of the HCK. In accordance, $\alpha$-SMA assembly was clearly detectable along intracellular stress fibers marking cellular transformation into a myofibroblastic phenotype (Funderburgh et al., 2001). In serum-containing three-dimensional collagen gels HCK were capable of matrix contraction, even without TGF $\beta 1$ stimulation. In summary, $5 \%$ FCS exerted a universal detrimental effect on the maintenance of the keratocyte phenotype. Hence, building an organotypic corneal construct from serum-fed HCK is not possible.
In summary, SV40-transformed HCK continued to proliferate in serum-free medium while maintaining the non-contractile state. They were able to respond to TGF $\beta 1$ stimulation by differentiating into a contractile myofibroblast phenotype. This completely differentiated phenotype was reversible by the adaption to serum-free culture conditions. Despite the ability of HCK to take on keratocyte-like characteristics, the question remains whether this state represents quiescent keratocytes or repair fibroblasts. Fini (Fini, 1999) has emphasised that once the keratocyte is activated to the repair fibroblast phenotype it can further differentiate to the myofibroblast. Despite this transformation, activated corneal fibroblasts and myofibroblasts are not terminally differentiated, but have the ability to transition into one another (Maltseva et al., 2001). Over time, repair fibroblasts gradually become more quiescent and take on a keratocyte-like appearance, while biochemically, they continue to resemble fibroblasts. Hence, definitive classification of HCK cells awaits further analysis and exploration of whether these cells might be capable of re-differentiating into quiescent keratocytes.

In conclusion, our results reveal that the HCK cell line mimics in vivo keratocytes in several aspects: HCK resemble the quiescent keratocyte phenotype under serum-starved conditions and shift to activated phenotypes in response to serum or TGF $\beta 1$. Hence, this cell line may provide a useful tool to study the responses of corneal fibroblast cells to diverse environmental factors in vitro. Furthermore, the serum-free stromal construct presents an ideal component of a mechanistic in vitro wound-healing model.

\section{References}

Assouline, M., Chew, S. J., Thompson, H. W. and Beuerman, R. (1992). Effect of growth factors on collagen lattice contraction by human keratocytes. Invest. Ophthalmol. Vis. Sci. 33, 1742-1755.

Barry-Lane, P. A., Wilson, S. E., Cavanagh, H. D. et al. (1997). Characterization of SV40-transfected cell strains from rabbit keratocytes. Cornea 16, 72-78.

Beales, M. P., Funderburgh, J. L., Jester, J. V. and Hassell, J. R. (1999). Proteoglycan synthesis by bovine keratocytes and corneal fibroblasts: maintenance of the keratocyte phenotype in culture. Invest. Ophthalmol. Vis. Sci. 40, 1658-1663.

Berryhill, B. L., Kader, R., Kane, B. et al. (2002). Partial restoration of the keratocyte phenotype to bovine keratocytes made fibroblastic by serum. Invest. Ophthalmol. Vis. Sci. 43, 3416-3421.

Borderie, V. M., Mourra, N. and Laroche, L. (1999). Influence of fetal calf serum, fibroblast growth factors, and hepatocyte growth factor on three-dimensional cultures of human keratocytes in collagen gel matrix. Graefes Arch. Clin. Exp. Ophthalmol.237, 861-869.

Engelke, M., Patzke, J., Tykhonova, S. et al. (2004). Assessment of ocular irritation by image processed quantification of cell injury in human corneal cell cultures and in corneal constructs. ATLA 32, 345-353.

Fini, M. E. (1999). Keratocyte and fibroblast phenotypes in the repairing cornea. Prog. Retin. Eye. Res. 18, 529-551. 
Fini, M. E. and Stramer, B. M. (2005). How the cornea heals: cornea-specific repair mechanisms affecting surgical outcomes. Cornea 24, 2-11.

Funderburgh, J. L., Funderburgh, M. L., Mann, M. M. et al. (2001). Proteoglycan expression during transforming growth factor beta -induced keratocyte-myofibroblast transdifferentiation. J. Biol. Chem. 276, 44173-44178.

Hoffschir, F., Ricoul, M., Lemieux, N. et al. (1992). Jumping translocations originate clonal rearrangements in SV40-transformed human fibroblasts. Int. J. Cancer. 52, 130-136.

Jester, J. V., Petroll, W. M., Barry, P. A. and Cavanagh, H. D. (1995). Expression of alpha-smooth muscle (alpha-SM) actin during corneal stromal wound healing. Invest. Ophthalmol. Vis. Sci. 36, 809-819.

Jester, J. V., Barry-Lane, P. A., Cavanagh, H. D. and Petroll, W. M. (1996). Induction of alpha-smooth muscle actin expression and myofibroblast transformation in cultured corneal keratocytes. Cornea. 15, 505-516.

Jester, J. V., Huang, J., Barry-Lane, P. A. et al. (1999). Transforming growth factor(beta)-mediated corneal myofibroblast differentiation requires actin and fibronectin assembly. Invest. Ophthalmol. Vis. Sci. 40, 1959-1967.

Jester, J. V., Jiying, H., Molai, A. and Maurer, J. K. (2001). Extent of initial corneal injury as a basis for alternative eye irritation tests. Toxicol. in Vitro 15, 115-130.

Jester, J. V. and Ho-Chang, J. (2003). Modulation of cultured corneal keratocyte phenotype by growth factors/cytokines control in vitro contractility and extracellular matrix contraction. Exp. Eye. Res. 77, 581-592.

Jester, J. V., Huang, J., Fisher, S. et al. (2003). Myofibroblast differentiation of normal human keratocytes and hTERT, extended-life human corneal fibroblasts. Invest. Ophthalmol. Vis. Sci. 44, 1850-1858.

Jester, J. V. (2006). Extent of corneal injury as a biomarker for hazard assessment and the development of alternative models to the Draize rabbit eye test. Cutan Ocul. Toxicol. 25, 41-54.

Kawakita, T., Espana, E. M., He, H. et al. (2006). Preservation and expansion of the primate keratocyte phenotype by downregulating TGF-beta signaling in a low-calcium, serum-free medium. Invest. Ophthalmol. Vis. Sci. 47, 1918-1927.

Kurosaka, H., Kurosaka, D., Kato, K. et al. (1998). Transforming growth factor-beta 1 promotes contraction of collagen gel by bovine corneal fibroblasts through differentiation of myofibroblasts. Invest. Ophthalmol. Vis. Sci. 39, 699-704.

Maltseva, O., Folger, P., Zekaria, D. et al. (2001). Fibroblast growth factor reversal of the corneal myofibroblast phenotype. Invest. Ophthalmol. Vis. Sci. 42, 2490-2495.

Masui, T., Wakefield, L. M., Lechner, J. F. et al. (1986). Type beta transforming growth factor is the primary differentiationinducing serum factor for normal human bronchial epithelial cells. Proc. Natl. Acad. Sci. U. S. A. 83, 2438-2442.

Masur, S. K., Dewal, H. S., Dinh, T. T. et al. (1996). Myofibroblasts differentiate from fibroblasts when plated at low density. Proc. Natl. Acad.Sci. U.S. A. 93, 4219-4223.

Maurer, J. K., Molai, A., Parker, R. D. et al. (2001). Pathology of ocular irritation with bleaching agents in the rabbit lowvolume eye test. Toxicol. Pathol. 29, 308-319.

Maurer, J. K., Parker, R. D. and Jester, J. V. (2002). Extent of initial corneal injury as the mechanistic basis for ocular irritation: key findings and recommendations for the development of alternative assays. Regul. Toxicol. Pharmacol. 36, 106-117.

Mossman, T. (1983). Rapid colorimetric assay for cell growth and survival-application to proliferation and cytotoxicity assays. J. Immunol. Methods 65, 55-63.

Petridou, S., Maltseva, O., Spanakis, S. and Masur, S. K. (2000). TGF-beta receptor expression and smad2 localization are cell density dependent in fibroblasts. Invest. Ophthalmol. Vis. Sci. 41, 89-95.

Wilson, S. E., Lloyd, S. A., He, Y. G. and Mccash, C. S. (1993). Extended life of human corneal endothelial cells transfected with the SV40 large T antigen. Invest. Ophthalmol. Vis. Sci. 34, 2112-2123.

Wilson, S. E., Weng, J., Blair, S. et al . (1995). Expression of E6/ E7 or SV40 large T antigen-coding oncogenes in human corneal endothelial cells indicates regulated high-proliferative capacity. Invest. Ophthalmol. Vis. Sci. 36, 32-40.

Zorn-Kruppa, M., Tykhonova, S., Belge G. et al. (2004). Comparison of human corneal cell cultures in cytotoxicity testing. ALTEX 21, 129-134.

Zorn-Kruppa, M., Tykhonova, S., Belge, G. et al. (2005). A human corneal equivalent constructed from SV40-immortalised corneal cell lines. ATLA 33, 37-45.

\section{Acknowledgements}

The German Centre for Documentation and Evaluation of Alternatives to Animal Experiments (ZEBET, reference number FK31328-180 and WK1-1328-184) is acknowledged for funding.

\section{Correspondence to}

PD Dr. Maria Engelke

German Animal Welfare Federation - Animal Welfare

Academy

Spechtstrasse 1

85579 Neubiberg

Germany

e-mail: maria.engelke@tierschutzakademie.de, maria.engelke@yahoo.de 